Special issue of the International Conference on Computational and Experimental Science and Engineering (ICCESEN 2014)

\title{
Computer Aided Structral Analysis of a Tie Rod End
}

\author{
M. OZSOY ${ }^{a, *}$ AND M.K. PEHLIVAN ${ }^{b}$ \\ ${ }^{a}$ Sakarya University, Engineering Faculty, Mechanical Engineering Department, Sakarya, Turkey \\ ${ }^{b}$ Sakarya University, Institute of Naturel Science, Sakarya, Turkey
}

\begin{abstract}
The tie rod end is one of the most elementary parts of a steering mechanism, which has direct and crucial importance in terms of driving safety. The main function of this part is to transfer the routing, coming from the steering linkage, to steering knuckle via tie rot arm. In this study the structural analysis of a tie rod end part for a van-type vehicle is carried out by finite element (FE) modeling of the body, the joint and the bearing. Hence, unlike the previous studies in literature, each component of the tie rod end is included in FE model and a complete assembly is analyzed by means of contact interactions between parts. The analyses for the joint assembly are carried out for different possible tie-end orientations, and by this modeling approach, the stress variations and deformation characteristics of each component are investigated for different operational loading conditions.
\end{abstract}

DOI: 10.12693/APhysPolA.128.B-488

PACS: $81.70 . \mathrm{Bt}, 87.10 . \mathrm{Kn}$

\section{Introduction}

In the steering mechanism, the tie rod end undertakes the task of transferring the steering action from steering linkage to the wheels (Fig. 1). Hence the tie rod end requires a very detailed design and manufacturing process. Any malfunction of the tie rod end can cause acoustics and stability problems during driving. Falah et al. [1] have investigated the breaking problem of the tie rod end of a SUV, and found out, that the breaking occurs at $30000 \mathrm{~km}$, which makes the tie rod end not suitable for the 2 years $/ 60000 \mathrm{~km}$ warranty requirement implemented in Turkey [2]. According to the spectrum investigation, the tie rod end, manufactured with AISI 8620 steel, breaks due to fatigue. In 2013, Patil et al. [3] have calculated the natural frequency and the static stress of the tie rod end and the rod arm for a certain kind of vehicle. The whole mechanism was modeled as a single part, and the results of the static structural analyses showed that the mechanism was reliable.

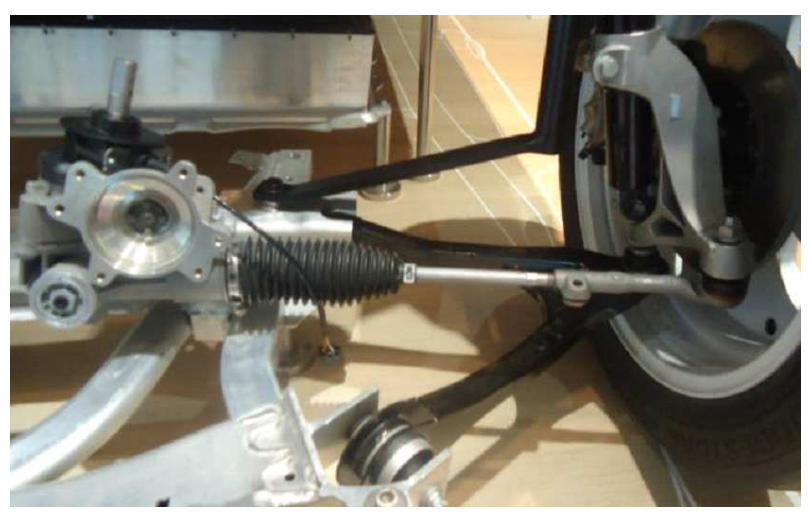

Fig. 1. Tie rod end and steering mechanism.

*corresponding author; e-mail: ozsoy@sakarya.edu.tr

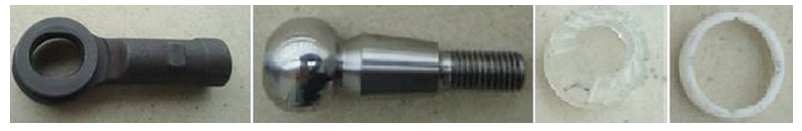

Fig. 2. Body, joint and bearings.

In this study, unlike in the previous reports, every single part in the tie rod end is modeled separately, and the contact relation between parts are defined in detail. The stress values for every single part are analyzed for different positions of the joint. In Fig. 2 the parts constituting the tie rod end are depicted. The mechanical properties of the part materials of tie rod end are given in Table I.

TABLE I

Material properties of bearing parts, joint and body [4].

\begin{tabular}{c|c|c|c}
\hline \hline & Bearing parts & Joint & Body \\
\hline Material & Ultraform & AISI 1040 & AISI 5140 \\
& N2320 POM & & \\
Elasticity modulus & $3 \mathrm{GPa}$ & $207 \mathrm{GPa}$ & $210 \mathrm{GPa}$ \\
Poisson ratio & 0.42 & 0.3 & 0.3 \\
Yield strength & $64 \mathrm{MPa}$ & $400 \mathrm{MPa}$ & $1165 \mathrm{MPa}$ \\
Tensile strength & $84 \mathrm{MPa}$ & $620 \mathrm{MPa}$ & $1310 \mathrm{MPa}$
\end{tabular}

\section{Geometric and mathematical modeling}

The geometrical model constitutes of the body, the joint, and the bearings. The bottom cover and the body are modeled as a single part. The geometrical model is created as a 3D solid in Ansys Workbench Design Modeller, while neglecting the parts that are thought as negligible in the analysis. In order to satisfy required tolerances of the analysis, different finite element meshes were investigated. Finally a finite element mesh consisting of 97173 elements was used. Such finite element mesh is illustrated in Fig. 3a. 


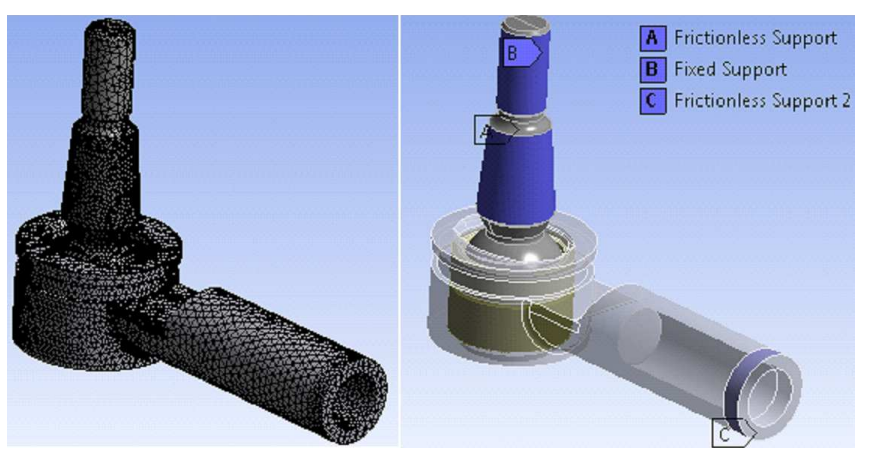

Fig. 3. (a) Tie rod end finite element mesh, (b) boundary conditions.

Frictionless support on the conical surface (A), where the joint merges with the steering knuckle, a fixed support on the surface, where the joint has its gears (B), and frictionless support on the surface, where joint connects to the rod arm (C), are defined as boundary conditions (Fig. 3b).

The contact types between the parts are depicted in Fig. 4a. Bonding contacts between the body and the bearings ( $\mathrm{A}$ and $\mathrm{B}$ ), frictional contacts between the joint and the bearings (C and D) are defined. The friction coefficient between the steel body and the POM bearings is defined as 0.22 [5]. In the case of small slipping, the friction coefficient does not change with applied force [6]. Hence, the preloading at the last stage of the assembly does not affect the friction coefficient.

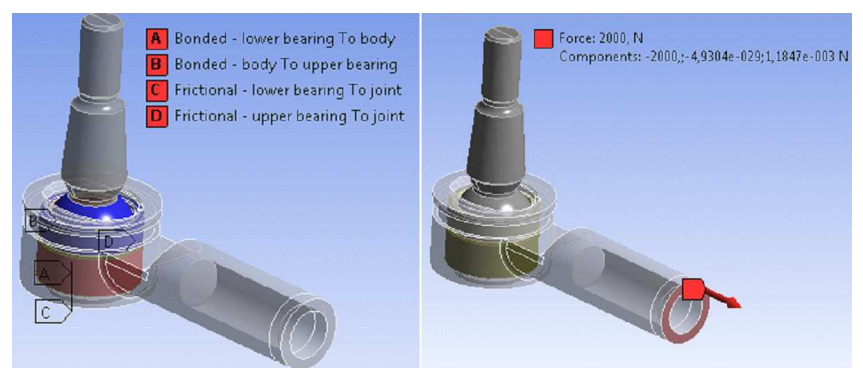

Fig. 4. (a) Contact surfaces, (b) static loading.

At the last step, the loading used for static analysis is defined as $2000 \mathrm{~N}$ along the $\mathrm{x}$-axis, according to the information provided by Teknorot A.S. (Fig. 4b). This loading condition represents the situation on the left tie rod for right direction steering or the right tie rod for left direction steering. Lee et al. [7] in their study for similar conditions used static loading of $1538 \mathrm{~N}$ for the tie rod end; hence it is considered that $2000 \mathrm{~N}$ loading is suitable for this study.

Although the joint is perpendicular to the body almost all the time, it has the ability to rotate and incline around the perpendicular axis for \pm 28 degrees. This way, even at the extreme steering angles, for varying road conditions, the driver is able to orient the vehicle as desired.
In this study, the static structural analyses for $0^{\circ}, 25^{\circ}$, $28^{\circ}$ locations of the joint were performed.

\section{Results of static structural analysis}

The static analysis is carried out for different inclination values of the joint; namely for 0 degrees, 25 degrees and for 28 degrees (the value at which the joint touches the body. The maximum stress values at different inclinations are listed for every part in Table II.

TABLE II

Stress values of parts of tie end rod at each angular position.

\begin{tabular}{c|c|c|c|c}
\hline \hline $\begin{array}{c}\text { Position } \\
\text { [degrees] }\end{array}$ & $\begin{array}{c}\text { Body } \\
\text { maximum } \\
\text { stress } \\
{[\mathrm{MPa}]}\end{array}$ & $\begin{array}{c}\text { Joint } \\
\text { maximum } \\
\text { stress } \\
{[\mathrm{MPa}]}\end{array}$ & $\begin{array}{c}\text { Lower } \\
\text { bearing } \\
\text { maximum } \\
\text { stress } \\
{[\mathrm{MPa}]}\end{array}$ & $\begin{array}{c}\text { Upper } \\
\text { bearing } \\
\text { maximum } \\
\text { stress } \\
{[\mathrm{MPa}]}\end{array}$ \\
\hline 0 & 150 & 211 & 6.5 & 8.6 \\
25 & 153.2 & 200.9 & 6.6 & 8.7 \\
28 (contact) & 160.8 & 182.7 & 6.1 & 9.1
\end{tabular}

\section{Conclusions}

The investigation on the structural static analysis shows that the stresses on the parts are smaller than their yield values. Based on the structural static analysis results, the maximum stresses for the joint, the body, and the bearings are $211 \mathrm{MPa}, 160.8 \mathrm{MPa}$ and $9.1 \mathrm{MPa}$ respectively. Although the largest stress value occurs on the joint, because of the high yield stress of AISI 5140 and the high stress/life values, the smallest safety factor has not the joint, but the body. Hence according to the results, deformation and breaking will occur on the body first. These results are similar with the malfunction data obtained from Teknorot A.S.

When the joint moves from perpendicular position to 25 degrees inclination, maximum stress decreases by $10 \mathrm{MPa}$. At the 28 degrees inclination, the value at which the joint touches the body, the maximum stress for the joint decreases by $13 \%$ and reaches the smallest value. On the other hand, with the increase in the inclination the stress value in the body increases and reaches the largest value $(160.8 \mathrm{MPa})$ at inclination of $28 \mathrm{de}-$ grees. The maximum stress values for the bearings occur at 28 degrees inclination as well, when the stress value at the upper bearing becomes 9.1 MPa.

The largest number of malfunctions occurs due to the deformations at the bearings, which is in accord with the data of the manufacturer Teknorot A.S. The stress values given in Table II show, that the stress values observed on the upper bearing is approximately 33\% larger than the ones observed on the lower bearing. The probable deformations due to this large difference can be eliminated by appropriate change in the material. 


\section{Acknowledgments}

The authors would like to thank Murat Isik, R\&D coordinator of Teknorot A.S. for his valuable assistance.

\section{References}

[1] A.H. Falah, M.A. Alfares, A.H. Elkholy, Eng. Fail. Anal. 14, 895 (2007).

[2] Regulations about warranty certificate implementation principals, The Official Gazette, 14.06.2003-25138.

[3] M.A. Patil, D.S. Chavan, M.V. Kavade, U.S. Ghorpade, Int. J. Appl. Innov. Eng. Manag. (IJAIEM) 2, $222(2013)$
[4] http://www.totalmateria.com, 24.11.2013.

[5] K. Shinohara, Thermoplastic Resin Composition Containing Mesoporous Powders Absorbed With Lubricating Oils, Patent WO 2006057974 A1, 1 June 2006.

[6] E. Rabinowicz, Friction and Wear of Materials, Wiley-Interscience, 1995.

[7] K.-H. Lee, J.K. Kim, Y.J. Kim, W.H. Yang, Y.C. Park, Int. J. Autom. Techn. 12, 375 (2011). 